\title{
Rhinolithiasis, a rare entity: Analysis of 31 cases and literature review
}

\author{
Nurullah Seyhun, () Ebubekir Toprak, (1) Kerem Sami Kaya, () Senem Kurt Dizdar, (i) Suat Turgut \\ Department of Ear Nose Throat Head and Neck Surgery, Sisli Hamidiye Etfal Training and Research Hospital, Istanbul, Turkey
}

\begin{abstract}
OBJECTIVE: Rhinolithiasis is a rare condition which results from deposition of salt around a endogenous or exogenous nidus. In the literature, most of the reports are single case studies. In this study, we aimed to present the characteristics, symptoms, diagnosis, and treatment methods of 31 rhinolithiasis cases and to focus on the current literature.

METHODS: We retrospectively reviewed 31 rhinolithiasis cases which have been diagnosed and treated in a tertiary care center between January 2014 and December 2018. Patient characteristics, presenting symptoms, concomitant sinonasal disorders, and type of surgery were noted. Descriptive statistics were carried out.

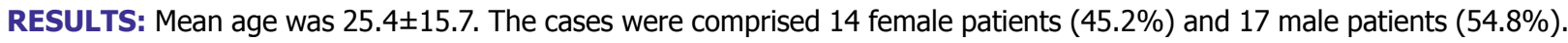
The most common presenting symptom was nasal obstruction (71\%). Malodorous unilateral rhinorrhea was present in 17 patients (54.8\%). Epistaxis snoring and sleep apnea were other rare symptoms. In 21 of the cases (67.7\%), rhinolith was located between inferior turbinate and septum which was the most common location seen in our series. The number of patients who were under the age of 18 was 13, in 2 of them, rhinolith was found to be formed around a plastic bead, and in 2 of them, fruit seeds were the nidus. The most common concomitant sinonasal pathology was septal deviation which was detected in 20 of the patients $(64.5 \%)$, adenoid vegetation and nasal polyposis were other disorders. In 20 of the patients $(64.5 \%)$, simple removal of the rhinolith using a forceps with the help of a rigid nasal endoscope was performed. Eight of the 17 patients had severe deviation and septoplasty was performed at the same time, which was the most common concomitant surgical intervention (25.8\%). In 3 patients (9.6\%), functional endoscopic sinus surgery was performed at the same time.

CONCLUSION: Our series is one of the largest series in the literature. The most common presenting symptom was nasal obstruction followed by malodorous rhinorrhea. Accompanying sinonasal disorders should be addressed to improve the outcome. Rigid or flexible endoscopic examination should be used to detect a rhinolith. Computed tomography scan can diagnose a hidden rhinolith in a patient with nasal obstruction.
\end{abstract}

Keywords: Nasal foreign body; nasal obstruction; rhinolith; rhinolithiasis.

Cite this article as: Seyhun N, Toprak E, Kaya KS, Kurt Dizdar S, Turgut S. Rhinolithiasis, a rare entity: Analysis of 31 cases and literature review. North Clin Istanb 2021;8(2):172-177.

$\mathrm{R}_{\mathrm{t}}^{\mathrm{h}}$ hinoliths are rarely encountered foreign bodies in the nasal cavity which is formed around an organic or inorganic, exogenous or endogenous nidus over a period of years [1]. Endogenous materials such as bone fragments, ectopic tooth, desquamated epithelium, and exogenous materials such as fruit seeds, plastic bodies, batteries, and stones can serve as the nidus around which the encrustation occurs [2-4]. The pathogenesis of the formation of rhinolith is not well known, however, several theories have been proposed. A widely accepted theory is that lodgment of a foreign body in the nasal cavity promotes an acute or chronic inflammation in the nasal

Received: July 01, 2020 Accepted: October 02, 2020 Online: October 26, 2020

Correspondence: Nurullah SEYHUN, MD. Sisli Hamidiye Etfal Egitim ve Arastirma Hastanesi, Kulak Burun Bogaz Bas Boyun Cerrahisi Klinigi, Istanbul, Turkey.

Tel: +90 2123735000 e-mail: seyhun90@hotmail.com

(c) Copyright 2021 by Istanbul Provincial Directorate of Health - Available online at www.northclinist.com 
mucosa which causes the precipitation of calcium and magnesium salts around the foreign body [5, 6]. Due to similar symptoms, rhinolithiasis can be easily misdiagnosed as chronic sinusitis [7]. A wide variety of presenting symptoms can be seen such as unilateral malodorous, nasal discharge, nasal obstruction, unilateral purulent rhinitis with or without sinusitis, facial pain and epistaxis. Furthermore, palatal [8] and septal perforation [9] may occur as a complication of rhinoliths.

In this study, we aimed to present the clinical and radiologic features of 31 rhinolithiasis cases, as well as concomitant sinonasal pathologies and demographic characteristics of the patients.

\section{MATERIALS AND METHODS}

This study was approved by the Ethical Committee of Sisli Hamidiye Etfal Training and Research Hospital with the approval number of 2485 and with approval date of August 20, 2019. We retrospectively reviewed 31 rhinolithiasis cases which have been diagnosed and treated in a tertiary care center between January 2014 and December 2018. As this is a retrospective chart review study, patient consent was not sought. Age, gender, clinical presentation, location of the rhinolith, and accompanying sinonasal pathologies were recorded for each patient. Anterior rhinoscopic and flexible or rigid nasal endoscopic examination were done to detect rhinoliths in all cases. In all cases, rhinolith removal with or without additional procedures for accompanying sinonasal disease was performed under sedation or general anesthesia with the use of 00 rigid endoscopy. All patients were evaluated with paranasal computerized tomography (CT) scan preoperatively except for seven child patients under the age of 16. CT scans of all patients and operation notes were retrospectively analyzed to detect the concomitant sinonasal diseases. Removal of rhinolith was carried out using forceps in the operating room. All patients were seen on the $7^{\text {th }}$ day postoperatively and followed up with nasal endoscopy on the $1^{\text {st }}$ month and up to 6 months postoperatively (1-6 months) to see if residual or recurrent disease is present.

\section{Statistical Analysis}

SPSS 24.0 (IBM Corp;; Armonk, NY, USA) program was used for statistical analysis. Descriptive statistics were given as means, standard deviation, minimum and maximum for numerical variables, and percentage and number for categorical variables.

\section{Highlight key points}

- Rhinolithiasis is a rare condition, which should be included in differential diagnosis in case of unilateral nasal obstruction or unilateral purulent rhinorrhea.

- Accompanying sinonasal disorders should be addressed to improve the outcome.

- Although it has never been reported, obstructive sleep apnea can also be the presenting symptom, especially in children.

- It is important to perform rigid or flexible nasal endoscopy to reveal any hidden stones in patients with nasal obstruction.

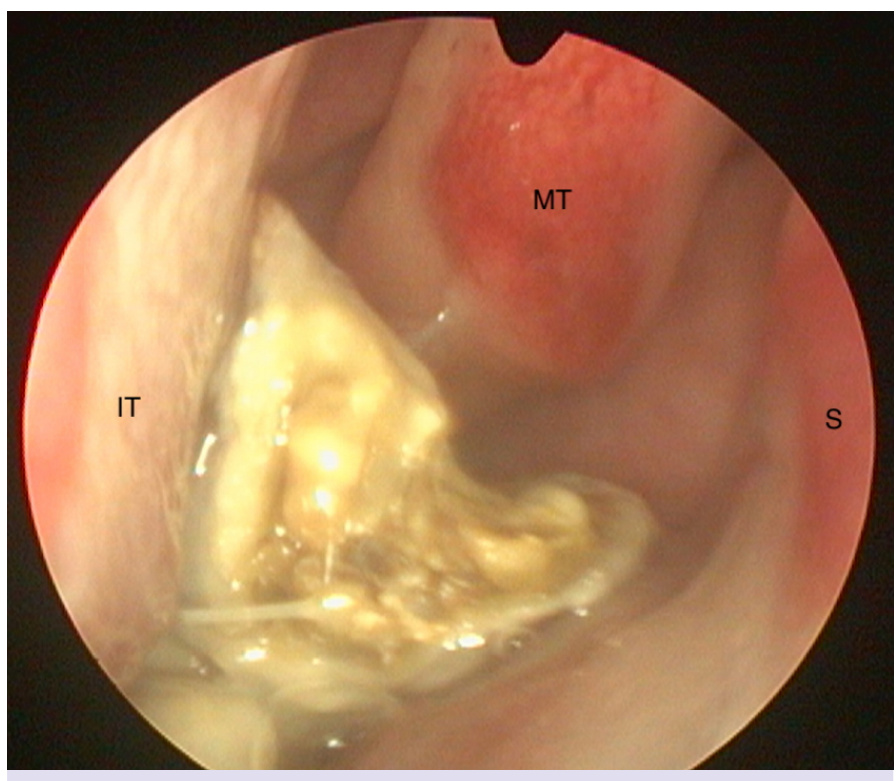

FIGURE 1. Rhinolith sitting between inferior turbinate and septum.

IT: Inferior turbinate; S: Septum; MT: Middle turbinate.

\section{RESULTS}

Medical charts of 31 patients were reviewed in total, mean age was $25.4 \pm 15.7$. The cases were comprised 14 female patients $(45.2 \%)$ and 17 male patients $(54.8 \%)$. In 22 of the cases, rhinolith was located on the right side (71\%), and 9 were located on the left side (29\%). The most common presenting symptom was nasal obstruction (71\%). Malodorous unilateral rhinorrhea was present in 17 patients $(54.8 \%)$. Epistaxis was seen in 5 of the patients $(16.1 \%)$, snoring and sleep apnea were other rare symptoms (both 3.2\%). In 21 of the cases (67.7\%), rhinolith was located between inferior turbinate and septum which was the most common location seen in our series (Fig. 1, 2). In 5 patients (16.1\%), rhinolith was located between lateral nasal wall and inferior turbinate. 


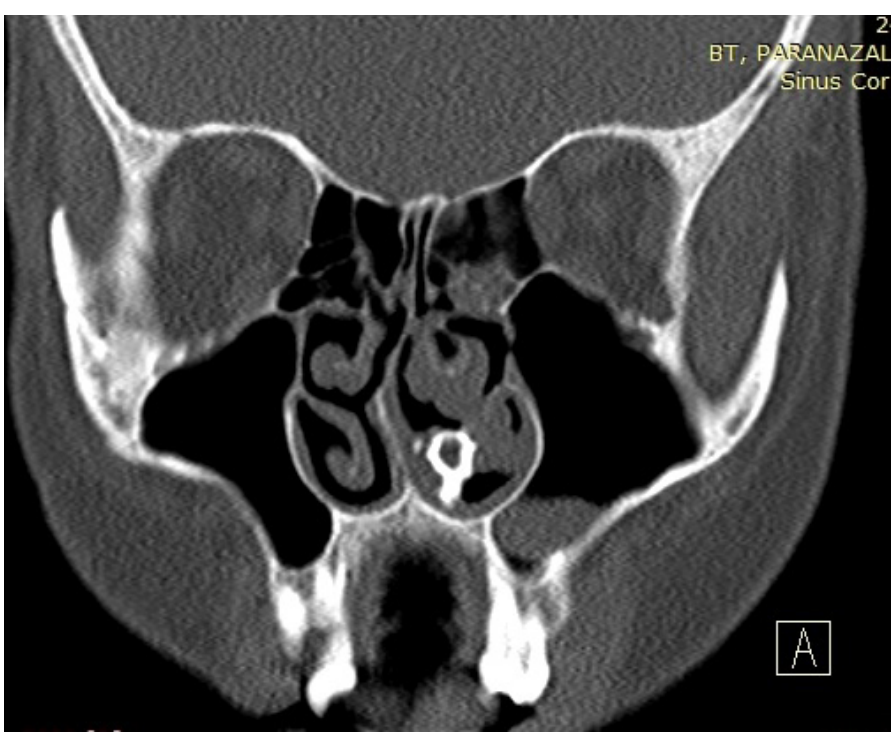

FIGURE 2. Computed tomography appearance of a rhinolith between inferior turbinate and septum on the left side.

Other rare locations of rhinolith were between middle turbinate and septum (9.7\%) and lateral to middle turbinate $(6.5 \%)$ (Table 1$)$.

The number of patients who were under the age of 18 was $13(41.9 \%)$, in 2 of them, rhinolith was found to be formed around a plastic bead, and in 2 of them, fruit seeds were the nidus. Any identifiable foreign body was not found in the rest of rhinoliths. None of the patients recalled a history of foreign body in nasal cavities.

In clinical examination, the most common concomitant sinonasal pathology was septal deviation which was detected in 20 of the patients $(64.5 \%)$, adenoid vegetation was seen in 2 patients $(6.4 \%)$, and nasal polyposis accompanied rhinolith in 1 case (3.2\%). In 11 of the patients, rhinolith was found to be on the same side with septal deviation (35.4\%), whereas in 9 patients, rhinolith was located on the contralateral side of septal deviation (29\%). On radiological evaluation, concomitant sinus disorders were detected in 14 patients (45.1\%). The most common concomitant sinus disorder was bilateral or unilateral (on the same side with rhinolith) mucosal thickening of maxillary sinus (29\%). Other concomitant sinus disorders are depicted in Table 2.

In 20 of the patients (64.5\%), simple removal of the rhinolith using a forceps with the help of a rigid nasal endoscope was performed. Eight of the 20 patients who had concomitant septal deviation had severe deviation and septoplasty was performed at the same time, which was the most common concomitant surgical intervention

\begin{tabular}{|c|c|c|}
\hline & Mean \pm SD & $\begin{array}{l}\text { Median } \\
\text { (Min-Max) }\end{array}$ \\
\hline \multirow[t]{2}{*}{ Age } & $25.4 \pm 15.7$ & $23(5-63)$ \\
\hline & $\begin{array}{c}\text { Number of } \\
\text { patients }\end{array}$ & Percentage \\
\hline \multicolumn{3}{|l|}{ Age groups (years) } \\
\hline$<18$ & 13 & 41.9 \\
\hline$>18$ & 18 & 58.1 \\
\hline \multicolumn{3}{|l|}{ Gender } \\
\hline Male & 17 & 54.8 \\
\hline Female & 14 & 45.2 \\
\hline \multicolumn{3}{|l|}{ Symptoms } \\
\hline Nasal obstruction & 22 & 71 \\
\hline Malodorous unilateral rhinorrhea & 17 & 54.8 \\
\hline Epistaxis & 5 & 16.1 \\
\hline Sleep apnea & 1 & 3.2 \\
\hline Snoring & 1 & 3.2 \\
\hline \multicolumn{3}{|l|}{ Side } \\
\hline Right & 22 & 71 \\
\hline Left & 9 & 29 \\
\hline \multicolumn{3}{|l|}{ Localization } \\
\hline Inferior turbinate/septum & 21 & 67.7 \\
\hline Inferior turbinate/lateral nasal wall & 5 & 16.1 \\
\hline Middle turbinate/septum & 3 & 9.7 \\
\hline Lateral to middle turbinate & 2 & 6.5 \\
\hline
\end{tabular}

SD: Standart deviation; Min: Minimum; Max: Maximum.

$(25.8 \%)$. One of these patients had severe nasal septal deformity and open approach extracorporeal septoplasty was performed to have better functional outcome, the rest of the septoplasties were performed endonasally. In 3 patients $(9.6 \%)$, functional endoscopic sinus surgery was performed at the same time to improve ventilation and to preserve functionality of the sinuses (Table 2). Recurrent or residual disease was not detected in followup in any of the patients.

\section{DISCUSSION}

Rhinolithiasis is a rare entity and the etiology is not clear. It is thought to be caused by a foreign body acting as nidus which produces inflammation and mineral salt deposition $[10,11]$. Most common presenting symptom is reported to be unilateral nasal obstruction followed by unilateral purulent rhinorrhea $[11,12]$. Facial pain, epis- 
TABLE 2. Accompanying sinonasal disorders and type of surgery

Number of Percentage patients

Accompanying sinonasal disorders

Septal deviation

64.5

Adenoid vegetation

6.4

Nasal polyposis

Bilateral or unilateral (on the same side with rhinolith) mucosal thickening of maxillary sinus

3.2

Bilateral or unilateral (on the same side with rhinolith) mucosal thickening of maxillary and ethmoid sinus

Pansinusitis on the same side with rhinolith

Retention cyst in maxillary sinus on the same side with rhinolith

Bilateral extensive type concha bullosa

Unilateral (on the same side with rhinolith) extensive type concha bullosa

$\begin{array}{cc}20 & 64.5 \\ 2 & 6.4 \\ 1 & 3.2 \\ 9 & 21.4 \\ 2 & 6.4 \\ 1 & 3.2 \\ 2 & 6.4 \\ 3 & 9.6 \\ 2 & 6.4 \\ & \\ 20 & 64.5 \\ 7 & 22.5 \\ 3 & 9.6 \\ 1 & 3.2\end{array}$

taxis, headache, and anosmia can also be seen as a result, however, it can be totally asymptomatic and can be incidentally detected in routine nasal examination or X-rays $[1,12]$. The first case in the literature was reported by Bartholin in 1654 [13], since then, more than 800 cases have been reported [12]. Females were affected more commonly than males in the previous studies $[1,10]$, however, in our study, a slight predomination of males was seen. Our study is composed of 31 cases, which is one of the largest case series in the literature.

In our study, the most common accompanying sinonasal pathology was septal deviation which was detected in 20 patients $(64.5 \%)$ which is slightly higher than reported literature $[11,14]$. Sinus disorders were detected in 14 patients (45.1\%). Ozdemir et al. [14] reported that accompanying sinusitis was detected in $52.4 \%$ of the patients, whereas Yildirim et al. [1] detected sinusitis in $25 \%$ of the rhinolithiasis patients. Obstruction caused by rhinolith could well be the reason for sinusitis, preparing a suitable environment for chronic inflammation, and alternatively, chronic sinusitis could also cause a formation of rhinolith by the chronically inflamed mucosa serving as an endogenous nidus [15]. For this reason, sinusitis is common in patients with rhinolithiasis. In our study, in 11 of the patients (35.4\%), rhinolith was located on the same side with septal deviation; in 9 patients (29\%) was on the contralateral side of sep- tal deviation. Adib et al. [10] suggested that stagnation in the nasal cavity posterior to a deviation perpetuates the precipitation of nasal debris and foreign bodies on a trapped nidus, and "eddy current" formed around the deviation or a spur, makes it easier to form a rhinolith on the same side with the deviation. On the contrary, Hadi et al. [16] reported that air turbulence on the contralateral side of deviation causes dryness and stagnation of secretions at the nasal floor might lead to the formation of stone. In our study, we have seen almost the same number of rhinoliths both on the same side and contralateral side of the deviation. Due to small size of reported cases, this point needs to be clarified in a large series.

In our series, 13 of the patients were under 18 years old (41.9\%). In 4 of them, we were able to identify plastic beads and fruit seeds as nidus. Children tend to place foreign bodies in orifices, especially in the period between 3 and 5 years of age [17]. If these foreign bodies are missed and not diagnosed, they may act as nidus and rhinolith may occur. In one of our cases, a 6-year-old male, the presenting symptom was obstructive sleep apnea and rhinolith was found incidentally without any coexisting upper airway pathology. Although it has never been reported, obstructive sleep apnea can also be the presenting symptom, especially in children. Since it might take years to develop a rhinolith around a nidus, it is important to manage nasal foreign bodies correctly in children to prevent 
morbidities such as rhinolith formation in the future. A detailed nasal examination is suggested in patients with unilateral nasal obstruction and/or malodorous rhinorrhea to reveal any underlying foreign body or rhinolith.

In our series, the most common localization of rhinolith was between inferior turbinate and septum, which is consistent with the previous studies $[2,11,18]$. We also observed that rhinoliths may lodge between lateral nasal wall and inferior turbinate, lateral to middle turbinate, and between middle turbinate and septum.

As concomitant sinonasal disorders are seen common with rhinolithiasis, it is important not to miss a rhinolith hiding behind a severe septal deviation or nasal polyp [19]. In a patient who was prepared for surgery for nasal polyposis, rhinolith was incidentally found between polyps on CT scan. In another patient who had severe septal deviation and in whom rigid endoscopy could not be performed on deviation side, rhinolith was hiding behind the deviation which was also detected on CT scan. Rigid endoscopy or flexible endoscopy is used to diagnose rhinolithiasis and due to opacity of calcified stones on plain X-rays and CT scan, these imaging methods are also very useful $[20,21]$. Simple removal of the rhinoliths using rigid endoscopes can be performed in suitable patients under local or general anesthesia. When there is a concomitant sinonasal disorder which needs to be addressed, appropriate treatment should be applied to increase the functional outcome. If the rhinolith cannot be removed due to size, ultrasound lithotripsy can be used to break up the stone, or simply breaking it up with forceps can be as useful [20]. In our series, 20 patients underwent simple removal of the rhinolith using forceps. In seven patients, septoplasty was also performed endonasally, and in one patient, extracorporeal open approach septoplasty was performed to correct severely deviated nasal septum. In three patients, endoscopic sinus surgery was carried out to improve and restore sinus functions. In three patients, bilateral extensive type concha bullosa was noted, in two patients, unilateral extensive type concha bullosa was present on the same side with rhinolith. The association of concha bullosa and rhinolith is yet to be investigated.

\section{Conclusion}

Although rhinolithiasis is a rare condition, it can cause significant nasal obstruction. The most common presenting symptom is unilateral nasal obstruction followed by unilateral malodorous rhinorrhea. Accompanying sinonasal disorders may be encountered such as septal deviation, nasal polyposis, and sinusitis. It is important to perform rigid or flexible nasal endoscopy to reveal any hidden stones in patients with nasal obstruction. CT scan can help identify the calcified stones in the nasal cavity. The treatment method of choice is simple removal of rhinolith with the use of rigid endoscope, however in patients with accompanying disorders, appropriate treatment should be applied to increase functional outcome. Larger series are needed to reveal the pathogenesis of this rare condition.

Ethics Committee Approval: The Ethics Committee of Sisli Hamidiye Etfal Training and Research Hospital provided the ethics committee approval for this study (date: 20.08.2019, number: 2485).

Conflict of Interest: No conflict of interest was declared by the authors.

Financial Disclosure: The authors declared that this study has received no financial support.

Authorship Contributions: Concept - NS, ET; Design - NS, KSK; Supervision - SKD, ST; Fundings - ST; Materials - ET, KSK; Data collection and/or processing - NS, ET; Analysis and/or interpretation - KSK, SKD; Literature review - NS, ST; Writing - NS; Critical review - ET, SKD, KSK, ST.

\section{REFERENCES}

1. Yildirim N, Arslanoglu A, Sahan M, Yildirim A. Rhinolithiasis: clinical, radiological, and mineralogical features. Am J Rhinol 2008;22:78-81.

2. Akkoca Ö, Tüzüner A, Demirci Ş, Ünlü C, Uzunkulaoğlu H, Arslan $\mathrm{N}$, et al. Patient characteristics and frequent localizations of rhinoliths. Turk Arch Otorhinolaryngol 2016;54:154-7. [CrossRef]

3. Zalagh M, Akhaddar A, Benariba F. Chronic rhinorrhea revealing an actinomycotic rhinolithiasis with ectopic tooth. Int J Oral Maxillofac Surg 2012;41:297-9. [CrossRef]

4. Senkal HA, Suslu AE, Unal OF. A rare cause of rhinolithiasis: ectopic tooth. Int J Pediatr Otorhinolaryngol 2006;1:249-52. [CrossRef]

5. Shaw LCK. Rhinolith of endogenous origin: a rare entity. Surg Pract 2007;11:48-50. [CrossRef]

6. Ezsiás A, Sugar AW. Rhinolith: an unusual case and an update. Ann Otol Rhinol Laryngol 1997;106:135-8. [CrossRef]

7. Send T, Jakob M, Eichhorn KW. Multiple causes for rhinolithiasis. Rhinology 2014;52:183-6. [CrossRef]

8. Pinto LS, Campagnoli EB, de Souza Azevedo R, Lopes MA, Jorge J. Rhinoliths causing palatal perforation: case report and literature review. Oral Surg Oral Med Oral Pathol Oral Radiol Endod 2007;104:e42-6.

9. Inaoka T, Nonomura M, Kikukawa T. Rhinolith with Nasal Septum Perforation. Practica Oto-Rhino-Laryngologica 2003;96:693-5.

10. Adib H, Natout MAE, Zaytoun G, Hadi UA. Rhinolithiasis: a misleading entity. Allergy Rhinol (Providence) 2018;9:2152656718783596.

11. Aksakal C. Rhinolith: Examining the clinical, radiological and surgical features of 23 cases. Auris Nasus Larynx 2019;46:542-7. [CrossRef]

12. Lahma J, Hejjouji R, Azzam I, Oujilal A, Essakalli L. Rhinolithiasis: about an observation of a rare condition. Pan Afr Med J 2018;31:78. 
13. Eliachar I, Schalit M. Rhinolithiasis. Report of eight cases. Arch Otolaryngol 1970;91:88-90. [CrossRef]

14. Ozdemir S, Akbas Y, Görgülü O, Selçuk T, Sayar C. Rhinolithiasis: review of 21 cases. Am J Rhinol Allergy 2010;24:136-9. [CrossRef]

15. Manning N, Wu P, Preis J, Ojeda-Martinez H, Chan M. Chronic sinusitis-associated antrolith. IDCases 2018;14:e00467. [CrossRef]

16. Hadi U, Ghossaini S, Zaytoun G. Rhinolithiasis: a forgotten entity. Otolaryngol Head Neck Surg 2002;126:48-51. [CrossRef]

17. Cetinkaya EA, Arslan İB, Cukurova İ. Nasal foreign bodies in children: Types, locations, complications and removal. Int J Pediatr Otorhino- laryngol 2015;79:1881-5. [CrossRef]

18. Brehmer D, Riemann $\mathrm{R}$. The rhinolith-a possible differential diagnosis of a unilateral nasal obstruction. Case Rep Med 2010;2010:845671.

19. Yılmaz S, Güven DG, Subaşı B, Güler ŞY, Güçlü E. A rhinolith surrounded by a nasal polyp. J Craniofac Surg 2010;21:1954-5. [CrossRef]

20. Yuca K, Caksen H, Etlik O, Bayram I, Sakin YF, Dülger H, et al. The importance of rigid nasal endoscopy in the diagnosis and treatment of rhinolithiasis. Auris Nasus Larynx 2006;33:19-22. [CrossRef]

21. Ayub-ur-Rehman, Muhammad MN, Moallam FA. Endoscopy in rhinolithiasis. J Coll Physicians Surg Pak 2012;22:601-3. 